ISSN 1023-6104

(c) Rajshahi University Zoological Society

\title{
Effects of native plants and IGRs on the development of Tetranychus urticae Koch (Acari: Tetranychidae)
}

\author{
N. Naher, T. Islam, M. M. Haque* and S. Parween \\ Department of Zoology, University of Rajshahi, Rajshahi 6205, Bangladesh \\ *Corresponding author
}

\begin{abstract}
Effect of the seed dust of yellow karavi (Nerium oleander L.), flower juice of akanda (Calotropis procera L.) and two IGRs (diflubenzuron and triflumeron) were observed on the development of two-spotted spider mite (TSSM), Tetranychus urticae Koch. The seed dust of yellow karavi and akanda juice delayed the development of T. urticae resulting the elongation of duration of different developmental periods. But, the last stage of development was not affected with these treatments. Similarly, the two IGRs also significantly extended the duration of different developmental stages except deutonymph to adult. The different doses of two plant materials and two IGRs produced different effects on the development of two-spotted spider mite.
\end{abstract}

Key words: Tetranychus urticae, Calotropis procera, Nerium oleander, diflubenzuron, triflumuron, developmental period

\section{Introduction}

Mites are major pest of vegetable crops, fruits, cut flowers and ornamental plants, throughout the world. Among the mites, the web spinners are known as spider mites. Out of more than 130 species of spider mites, the red spider mite or two-spotted spider mite (TSSM), Tetranychus urticae Koch (Acari: Tetranychidae) is a worldwide major pest species of agricultural crops (Ho, 2000; Takafuji et al., 2000). TSSM feeds on more than 180 host plants (Sim et al., 2003). An adult TSSM measuring $0.5 \mathrm{~mm}$ in length passes through egg, larva, protonymph and deutonymph stages before becoming an adult (Huffaker et al., 1969). One generation of TSSM is completed in 19 days, at $21-23^{\circ} \mathrm{C}$ (Mitchell, 1973); but at $30^{\circ} \mathrm{C}$ the development is completed in 12 days (Thomas, 2001). Several acaricides are listed for the control of TSSM by Herbert (1999). Abamectin has been reported to provide excellent suppression of TSSM (Zhang \& Sanderson 1990; Wright et al., 1984); Pyridaben can control young stages of the mite (Sekulic, 1995).

Due to the harmful effect of the residual toxicity of the chemical neurotoxic insecticides on human and environment, control agents with comparative safety are searching by the entomologists. The systemic synthetic mimics of the insect hormones, which are best known as Insect Growth Regulators (IGRs) have been reported to be potent control agents against a number of pest insect of agriculture and fruit orchards (Fox, 1990). Among the IGRs, Diflubenzuron and Triflumuron are compounds which act as larvicides inhibiting larval molting, (Mulder \& Gijswijt, 1973) and extend developmental time (Neumann \& Guyer, 1987) in different insect species. These compounds are non-toxic to non-target organisms. Presently, plant materials are gaining importance in the field of insect management. Besides the neem, a number of native plants are providing better as growth deterrents. The present paper deals with the determination of the effects of seed dust of yellow karavi (Nerium oleander L.), flower juice of akanda (Calotropis procera L.) and two IGRs (Diflubenzuron and Triflumuron) on the development of the TSSM (T. urticae).

\section{Materials and Methods}

Source of TSSM: The culture of TSSM was maintained on bean plants in the laboratory of the Department of Zoology, Rajshahi University. Adults were collected from the laboratory culture and reared on potted young bean plants.

Collection of female TSSM: Adult female TSSM were collected with the help of a brush. The females were differentiated by their round caudal end and larger size with pointed posterior end.

Rearing of female TSSM: The females were released on leaf discs in the laboratory. Leaf discs were made with fresh bean leaf without any infestation. The leaf was cut into an area of $1.44 \mathrm{~cm}^{2}(1.2 \mathrm{~cm} \times 1.2 \mathrm{~cm})$. The leaf disc was then placed on cotton bed on a petridish $(5 \mathrm{~cm}$ $\times 1 \mathrm{~cm}$ ) facing the underside upward. The bed was soaked with water to keep it wet.

Collection of eggs: One or two female TSSM were kept on each disc for two hours. If eggs were laid, the mites were removed from the disc. Only one egg was kept on each disc and the others were removed. In this way required numbers of eggs were collected. Egg to adult development was completed on the leaf disc in the laboratory.

Plant materials used: Seeds of karavi and flower juice of the akanda (Giant milk weed) were used in this experiment. 
Collection of Karavi seeds: Fruits of karavi were collected from Rajshahi University campus. The seeds were taken out from the fruit, cut into thin slices and dried well under the sun. The dried seed slices were finely ground with an electric grinder.

Collection of flower juice of akanda: The fresh flowers of the akanda plant were collected from the bank of the river Padma, situated on the south side of Rajshahi University campus. The flowers were brought to the laboratory and crushed in an electric blender. The juice obtained was sieved through a sterilized metal wire sieve to separate the juice from the crushed petals.

Preparation of doses: For the preparation of stock solution distilled water of required volume was used with either seed dust or flower juice.

Karavi seeds: In $10 \mathrm{ml}$ of distilled water $0.5 \mathrm{~g}$ of seed dust was mixed thoroughly using an electric blender. When $0.02 \mathrm{ml}$ of this solution was sprayed on a leaf disc $\left(1.44 \mathrm{~cm}^{2}\right)$ the dose was obtained as $0.001 \mathrm{~g} / 1.44$ $\mathrm{cm}^{2}$ or. 694.44 ng. $\mathrm{cm}^{-2}$, which was the first dose. The next two doses were prepared by adding 20 and $40 \mathrm{ml}$ of water with $0.5 \mathrm{~g}$ of seed dust, which sprayed on the leaf discs and attained doses as 347.22 ng. $\mathrm{cm}^{-2}$ and 173.61 ng. $\mathrm{cm}^{-2}$ respectively.

Akanda flower juice: The stock solution was prepared by adding $2 \mathrm{ml}$ of distilled water with $1 \mathrm{ml}$ of raw juice. When $0.02 \mathrm{ml}$ of their solution was sprayed on the leaf disc, the dose, obtained was 4632 nl. $\mathrm{cm}^{-2}$. By adding 4 and $8 \mathrm{ml}$ of water with $1 \mathrm{ml}$ of juice and sprayed on the leaf discs, Thus attaining the doses as 2316 nl. $\mathrm{cm}^{-2}$ and $1158 \mathrm{nl} . \mathrm{cm}^{-2}$ respectively.

IGRs: Two IGRs of benzoylphenyl urea group were used in this experiment. These were Dimilin (a.i. 25\% WP diflubenzuron) and Baycidal (a.i. 25\% WP triflumuron), supplied respectively by the PhilipDuphar and Bayer, UK.

Preparation of doses: Both the compounds of $0.01 \mathrm{mg}$ weight were separately dissolved in $10 \mathrm{ml}$ of water. When $0.03 \mathrm{ml}$ of each of the solution was sprayed on the leaf disc, the concentration obtained was 5.208 ng. $\mathrm{cm}^{-2}$. By dissolving $0.02 \mathrm{mg} . \mathrm{cm}^{-2}$ IGRs in 20 and $40 \mathrm{ml}$ of water, other doses obtained were $2.604 \mathrm{nlcm}^{-2}$ and $1.302 \mathrm{nl} . \mathrm{cm}^{-2}$ respectively.

Experimentation: Sets of 30 leaf discs treated with each dose of each of the plant extracts or IGRs were prepared. Another 30 untreated leaf discs were placed on the wet cotton bed in petridish as control. The adult females allowed to oviposit on these leaf discs. After egg laying the females were removed, and single egg/disc was kept in all the petridishes that were covered keeping a slight gap to check excessive evaporation. All the eggs were carefully checked once every day and the life stages of TSSM up to adult emergence were recorded. The leaf discs in treated and control batches were changed with fresh discs of treated and untreated ones after 3-4 days. The experiment was carried out from May to July in the laboratory at $\mathrm{ca} .20^{\circ}-23^{\circ} \mathrm{C}$.

\section{Results and Discussion}

Effects of the plant extracts and IGRs on the duration of the developmental stages of T. urticae are presented in Tables 1 and 2.

Incubation period: Embryonic development of the eggs laid on the leaf discs treated with $N$. oleander and $C$. procera was delayed, compared to the eggs laid on the untreated leaf discs (Table 1). The seed dust of $N$. oleander was found to be more effective than the flower juice of $C$. procera. The seed dust prolonged the incubation period of TSSM with the increase of doses. Both diflubenzuron and triflumuron delayed the incubation period of TSSM eggs compared to the control (Table 1). The doses of the IGRs produced significantly different effects $(\mathrm{F}=23.43, \mathrm{P}<0.001)$.

Larval period: Treatment with the flower juice of $C$. procera did not affect the larval development, but the seed dusts of $N$. oleander at doses 387.22 and 694.44 ng. $\mathrm{cm}^{-2}$ increased the larval period of TSSM significantly (Table 1). Both IGRs increased the larval period of the mite with the increased doses $(F=31.22$, $\mathrm{P}<0.001)$.

Protonymphal period: Both the plant caused prolongation of the protonymphal period of T. urticae. The maximum protonymphal period was $1.94 \pm 0.01$ (at 694.44 nl. $\mathrm{cm}^{-2}$ ) and $1.74 \pm 0.06$ (at 4632 nl. $\mathrm{cm}^{-2}$ ) days in treated leaf discs with the seed dusts of $N$. oleander and flower juice of $C$. procera, respectively. Effect of both plant extracts significantly lengthened the protonymphal period compared to the protonymphal period in the control (Table 1). Among the IGRs, triflumuron at $5.21 \mathrm{ng} / \mathrm{cm}^{2}$ increased the protonymphal period (2.13 \pm 0.07 days) of TSSM was more than the similar dose level of diflubenzuron (Table 2). Other doses of the IGRs produced equal effect, which was significantly different from the effect produced in the control. 
Table 1. Mean \pm sd duration of different developmental stages of $T$. urticae treating with the seed dust of $N$. oleander and flower juice of $C$. procera $(n=30)$

\begin{tabular}{l|lllll}
\hline \multirow{2}{*}{$\begin{array}{c}\text { Dose } \\
(\text { ng.cm }\end{array}$} & \multicolumn{5}{c}{ Duration of developmental period (days) } \\
\cline { 2 - 6 } & Incubation & Larval & Protonymphal & Deutonymphal & Egg-Adult \\
\hline N. oleander & & & & & \\
193.61 & $2.44 \pm 0.11^{\mathrm{b}}$ & $1.39 \pm 0.09^{\mathrm{b}}$ & $1.69 \pm 0.07^{\mathrm{b}}$ & $1.63 \pm 0.25^{\mathrm{c}}$ & $7.63 \pm 0.22^{\mathrm{a}}$ \\
387.22 & $2.67 \pm 0.09^{\mathrm{c}}$ & $1.72 \pm 0.08^{\mathrm{b}}$ & $1.63 \pm 0.11^{\mathrm{b}}$ & $2.25 \pm 0.28^{\mathrm{b}}$ & $8.19 \pm 0.09^{\mathrm{c}}$ \\
694.44 & $3.10 \pm 0.15^{\mathrm{d}}$ & $2.30 \pm 0.15^{\mathrm{c}}$ & $1.94 \pm 0.10^{\mathrm{c}}$ & $2.17 \pm 0.16^{\mathrm{b}}$ & $9.44 \pm 0.31^{\mathrm{d}}$ \\
Control & $1.60 \pm 0.07$ & $1.00 \pm 0.26^{\mathrm{a}}$ & $1.30 \pm 0.11$ & $2.32 \pm 0.18^{\mathrm{a}}$ & $7.72 \pm 0.32^{\mathrm{b}}$ \\
\hline $\boldsymbol{C}$. procera & & & & \\
1158 & $2.65 \pm 0.08^{\mathrm{b}}$ & $0.90 \pm 0.12^{\mathrm{a}}$ & $1.45 \pm 0.07^{\mathrm{b}}$ & $2.25 \pm 0.10^{\mathrm{b}}$ & $7.50 \pm 0.06^{\mathrm{b}}$ \\
2316 & $2.65 \pm 0.11 \mathrm{~b}$ & $0.95 \pm 0.12^{\mathrm{a}}$ & $1.67 \pm 0.04^{\mathrm{c}}$ & $2.36 \pm 0.12^{\mathrm{a}}$ & $7.64 \pm 1.18^{\mathrm{c}}$ \\
4632 & $2.85 \pm 0.09^{\mathrm{c}}$ & $1.00 \pm 0.11^{\mathrm{a}}$ & $1.74 \pm 0.06^{\mathrm{c}}$ & $2.10 \pm 0.04^{\mathrm{c}}$ & $7.69 \pm 0.24^{\mathrm{c}}$ \\
Control & $2.00 \pm 0.110^{\mathrm{a}}$ & $0.90 \pm 0.07^{\mathrm{a}}$ & $1.30 \pm 0.11^{\mathrm{a}}$ & $2.39 \pm 0.07^{\mathrm{a}}$ & $6.59 \pm 0.15^{\mathrm{a}}$ \\
\hline
\end{tabular}

Means with the same letters do not differ significantly at $\mathrm{P}=0.05$ level

Table 2. Mean \pm sd duration of different developmental stages of $T$. urticae treating with diflubenzuron and triflumuron $(\mathrm{n}=30)$

\begin{tabular}{l|llccc}
\hline \multirow{2}{*}{$\begin{array}{c}\text { Dose } \\
\text { (ng.cm }\end{array}$} & \multicolumn{4}{c}{ Duration of developmental period (days) } \\
\cline { 2 - 5 } Diflubenzuron & Incubation & Larval & Protonymphal & Deutonymphal & Egg-Adult \\
1.302 & & & & \\
2.604 & $2.75 \pm 0.08^{\mathrm{b}}$ & $1.40 \pm 0.10^{\mathrm{bc}}$ & $1.60 \pm 0.08^{\mathrm{b}}$ & $1.81 \pm 0.19^{\mathrm{c}}$ & $7.69 \pm 0.12^{\mathrm{b}}$ \\
5.21 & $2.80 \pm 0.05^{\mathrm{b}}$ & $1.30 \pm 0.11^{\mathrm{b}}$ & $1.70 \pm 0.02^{\mathrm{bc}}$ & $2.50 \pm 0.16^{\mathrm{b}}$ & $8.33 \pm 0.22^{\mathrm{c}}$ \\
Control & $2.85 \pm 0.08^{\mathrm{bc}}$ & $1.40 \pm 0.12 \mathrm{~b}^{\mathrm{c}}$ & $1.65 \pm 0.11^{\mathrm{b}}$ & $2.50 \pm 0.12^{\mathrm{b}}$ & $8.11 \pm 0.08^{\mathrm{c}}$ \\
\hline Triflumuron & $2.30 \pm 0.11^{\mathrm{a}}$ & $0.90 \pm 0.07 \mathrm{a}$ & $1.30 \pm 0.1 \mathrm{a}$ & $2.38 \pm 0.07 \mathrm{a}$ & $7.00 \pm 0.12^{\mathrm{a}}$ \\
1.302 & & & & \\
2.604 & $2.75 \pm 0.06^{\mathrm{b}}$ & $1.40 \pm 0.10^{\mathrm{c}}$ & $1.55 \pm 0.14^{\mathrm{b}}$ & $2.57 \pm 0.11^{\mathrm{b}}$ & $8.21 \pm 0.4^{\mathrm{b}}$ \\
5.21 & $2.90 \pm 0.07^{\mathrm{c}}$ & $1.15 \pm 0.06^{\mathrm{b}}$ & $1.70 \pm 0.08^{\mathrm{c}}$ & $2.21 \pm 0.12^{\mathrm{a}}$ & $8.0 \pm 0.06^{\mathrm{b}}$ \\
Control & $2.70 \pm 0.01^{\mathrm{b}}$ & $1.45 \pm 0.14^{\mathrm{c}}$ & $2.13 \pm 0.07 \mathrm{~d}$ & $2.36 \pm 0.10^{\mathrm{a}}$ & $8.64 \pm 0.22^{\mathrm{c}}$ \\
\hline
\end{tabular}

Means with the same letters do not differ significantly at $\mathrm{P}=0.05$ level

Deutonymphal period: Both the plant extracts cause the decrease the of the deutonymphal period of TSSM compared to the control (Table 1). However, the effect was not related to the dose levels of the extracts, and was not statistically significant. In case of IGRs the effect on the deutonymphal period varied with the compounds and their doses (Table 2). Diflubenzuron doses increased the deutonymphal period significantly, but lowest dose (1.302 ng. $\mathrm{cm}^{-2}$ ) reduced the duration at maximum level. Triflumuron similarly resulted in maximum reduction in deutonymphal duration at minimum dose level (1.302 ng. $\left.\mathrm{cm}^{-2}\right)$, whereas, there was no effect of the higher two doses (Table 2). The ANOVA test showed no significant effect of both treatments on the duration of the deutonymphal period of TSSM.

Egg-to-adult developmental period: Total developmental time (egg-adult) required mere in the mites that develop on leaf disc treated with plant materials or IGRs. The effect was more pronounced and dose depended in plant treatment (Table 1 ), and $N$. oleander affected the developmental time more than $C$. procera. IGRs also lengthened the developing time of the mite compared to the control mites (Table 2), and both diflubenzuron and triflumuron affected the egg-adult development similarly. The present results revealed that both the plant materials and IGRs have effectively slowed down the developmental time in T. urticae.

Saenz de Cabenzon et al. (2002) studied the effect of triflumeron on the developing stage of $T$. urticae and found no toxicity on the egg stage of that mite. But, they mentioned that the immatures are 3.8 times susceptible to triflumeron than the adults. They also commented that triflumeron could be an interesting incorporation in the integrated pest programs of $T$. urticae. Saenz de Cabenzon et al. (2006) observed that the net reproductive rate, the intrinsic rate of increase and the finite rate of $T$. urticae female treated with triflumeron were lower than in those non treated, resulting in a reduction of population growth.

Diflubenzuron causes the inhibition of embryogenesis in the egg of several citrus root weevils when they fed on the treated foliage (Lovstran and Beavers, 1980; Schroeder et al. 1976). In addition Schroeder et al. (1976) found that the foliage spray of diflubenzuron reduced the egg hatch of Diaprepes abbreviatus (L) for 10 days. Shi et al. (2004) and Shi et al. (2006) studied the effect of plant extract on T. urticae. They found that the extracts of Kochis scopia and Stellera chamaejasme both had contact and systemic toxicity to 
the mite. Both the IGRs used here extended the developmental period of $T$. urticae by delaying the developmental rate. The two plant extracts also slowed down the developmental period. Further experiment can explore more effectiveness of these plant materials and IGRs.

\section{References}

Fox, P. 1990. Insect Growth Regulators. PJB Publ. Ltd. Richmond, UK. 102 pp.

Herbert, D.A, Jr. 1999. Peanut production guide: Insect control in peanuts. Tidewater Agricultural Research and Extension Center. http://vaes.vt.edu/tidewater/ peanut.

Ho, C.C. 2000. Spider mite problems and control in Taiwan. Exp. Appl. Acarol. 24: 453-462.

Huffaker, C.B., van de Vrie, M. \& McMurty, J.A. 1969. The ecology of tetranychid mites and their natural control. Ann. Rev. Entomol. 14: 125-174.

Lovstran, S.A. \& Beavers, J.B. 1980. Effect of diflubenzuron on four species of wiivils attackink citrus in Florida. Florida Entomol. 63(1): 112-115.

Mitchell, R. 1973. Growth and population dynamics of a spider mite (Tetranychus urticae K., Acarina: Tetranychidae). Ecology 54: 1349-1355.

Mulder, R. \& Gijswijt, M.J. 1973. The laboratory evaluation of two promising new insecticides which interfere with cuticle deposition. Pestic. Sci. 4: 737-745.

Neumann, R. \& Guyer, W. 1987. Biochemical and toxicological difference in mode of action of the benzoylureas. Pestic. Sci. 20: 147-156.

Saenz de Cabenzon, F.J., Perez-Moreno, I. \& Marco, V. 2002. Effects of triflumuron on the two-spotted spider mite, Tetranychus urticae (Acari: Tetranychidae) Exp. Appl. Acarol. 26(1-2): 71-78.

Saenz de Cabenzon, F.J., Martinez-Viller, Moreno, F., Marco, Vand \& Perez-Moreno. I. 2006. Influence of sublethai exposure to triflumuron on the biological performance of Tetranychus urticae Koch (Acari: Tetranychidae). http://www.fotosaf.com/siar ist/siar 042 08a.html.
Schroeder, W.J., Beavers, B.J., Sutton, R.A. \& Selhime, A.G. 1976. Ovicidal effect of Thompson-hayard TH-6040 in Draprepes abbreviatus on citrus in Florida. J. econ. Entomol. 69(6): 780-782.

Sekulic, D.R. 1995. The effects of hexythiazox, pyridaben, and flucycloxuron on the population growth of Tetranychus urticae Koch. (Acari: Tetranychidae). Pesticide 10: 25-33.

Sim, C., Seo, E. \& Cho, K. 2003. Life table and sensitivity analysis as fitness evaluation method of fenpyroximate and pyridaben resistant two-soptted spider mite (Tetranychus urticae Koch). J. Asia-Pacific Entomol. 6: 193-199.

Shi, G.L., Liu, S.Q., Cao, H. \& Li, S.Y. 2004. Acaricidal activities of Stellera chamaejasme against Tetranychus viennensis (Acari: Tetranychidae). J. econ. Entomol. 97(6): 1912-1916.

Shi Gl, , Zhao, L.L., Liu, S.Q., Cao, H., Clarke, S.R. \& Sun, J.H. 2006. Acaricidal activities of Kochia scoparia against Tetranychus urticae Tetranychus cinnabarinus and Tetranychus viennensis (Acari: Tetranychidae). J. econ. Entomol. 99(3): 858-863.

Takafuji, A., Ozawa, A., Nemoto, H. \& Gotoh, T. 2000. Spider mites of Japan: their biology and control. Exp. Appl. Acarol. 24: 319-335.

Thomas, C. 2001. Biological control of two-spotted spider mite. Integrated Pest Management Program, Pennsylvania Department of Agriculture. http:// paipm.cas.psu.edu/BugAg Bug/BAB-July2001.html.

Wright, D.J., Roberts, I.T.J., Androher, A., Green, A.S.J. \& Dybas, R.A. 1984. The residual activity of abamectin (MK-936) against Tetranychus urticae (Koch) on cotton. Meded. Fac. Landbouwwet. Rijksuniv 50: 633-637.

Zhang, Z. \& Sanderson, J.P. 1990. Relative toxicity of abamectin to the predatory mite Phytoseiulus persimilis (Acari: Phytoseiidae) and two-spotted spider mite (Acari: Tetranychidae). J. econ. Entomol. 83: 1783-1790.

Revised manuscript received on 12 May 2007. 